\title{
A vueltas con la descolonización: propuestas para algunas conceptualizaciones coloniales
}

\section{Grappling with Decolonization: Proposals for Some Colonial Conceptualizations}

\author{
Itzea Goikolea-Amiano \\ SOAS-Universidad de Londres (Reino Unido) \\ ig12@soas.ac.uk
}

\section{Resumen}

A la luz de los debates sobre el legado colonial que están teniendo lugar en el ámbito académico y en la sociedad civil en los últimos años, este artículo propone algunas herramientas teórico-metodológicas para concebir "lo colonial" de manera crítica y de(s)colonial. Proponemos abordar dicha categoría como una construcción compleja en cuya configuración los sujetos, las epistemologías y las estructuras sociopolíticas colonizadas jugaron un papel importante. Basándonos en diferentes trabajos académicos, planteamos dar visibilidad a la heterogeneidad y realizar comparativas históricoespaciales para evitar los esencialismos. Además, desarrollamos algunos ejemplos empíricos del Marruecos colonial relacionados con el género y la "desacralización de la historia".

\section{Palabras clave}

Colonialismo, de(s)colonial, Marruecos, islam, género.

\begin{abstract}
In light of the discussions on the legacies of colonialism which are recently taking place among scholars and civil society, this article suggests some theoretical-methodological tools to study the colonial past in a critical and "decolonial" way. We suggest to envision that category as a complex construction, in the shaping of which the colonised subjects, epistemologies, and socio-political structures played an important role. Building on a variety of works, we advance the usefulness of making the heterogeneity of perspectives visible and of making historical and spatial comparisons to avoid essentialisms. We also draw on some empirical examples from colonial Morocco related to gender and the "desacralization of history".
\end{abstract}

\section{Keywords}

Colonialism, decolonial, Morocco, Islam, gender. 


\section{Pensamiento e historiografías coloniales, postcoloniales y des-coloniales}

El carácter estructural del pensamiento y praxis colonial es uno de los mayores impedimentos a la hora de deshacernos del mismo, y prueba de ello son los retos a los que se enfrentan las diferentes iniciativas actuales que buscan poner en marcha la descolonización de las instituciones públicas, el discurso mediático, las dinámicas sociales a nivel local y de barrio, y también de las aulas y los curricula escolares y académicos. Este artículo tiene como objetivo proponer herramientas teórico-metodológicas para el estudio del pasado colonial que nos permitan aproximarnos al mundo postcolonial actual de una manera crítica, a la vez que histórica. La conceptualización de colonialismo que subyace dichas iniciativas, basadas en gran medida en el denominado "pensamiento decolonial" o "giro epistémico decolonial" desarrollado en el ámbito latinoamericano en las últimas dos décadas, peca de maniqueísmo y de falta de historicidad que, lejos de descolonizar, refuerza las epistemes coloniales y las falacias en las que a menudo se basan.

Si los estudios postcoloniales desarrollados en las décadas de 1980 y 1990 se centraban en el colonialismo contemporáneo británico y francés, el punto inicial de la genealogía de la colonialidad de los estudios decoloniales es 1492, fecha del inicio de la conquista española de las Américas. Además, estos últimos se centran en el concepto de la "colonialidad". La "colonialidad" se diferenciaría del colonialismo en tanto en cuanto el segundo es un evento que se sitúa en una época histórica concreta, mientras que la "colonialidad".

trasciende la historia; es el aparato de poder que se gesta en el periodo colonial y se refiere a la forma en que el trabajo, el conocimiento, la autoridad y las relaciones intersubjetivas se articulan entre sí, a través del mercado capitalista mundial, la idea de raza y el sistema de sexo-género. ${ }^{1}$

El sufijo "post-" en los estudios postcoloniales es problemático por cuanto sugiere una ruptura histórica que ensombrece las continuidades entre lo colonial y el periodo posterior a las independencias. ${ }^{2}$ La ruptura con los regímenes coloniales modernos que las independencias introdujeron no acabó, como no podía ser de otra forma, con toda una serie de epistemologías y modus operandi coloniales a partir de las cuales se configuraban las relaciones de poder. Precisamente por ello, sugiero que para abordar la complejidad de la herencia colonial actual necesitamos una comprensión del pasado que sea también compleja, especialmente en lo que al mundo colonizado se refiere. Así pues, propondré que lo colonial debe ser abordado como resultado de encuentros históricos, como una

\footnotetext{
${ }^{1}$ Sirin Adlbi Sibai, La cárcel del feminismo: hacia un pensamiento islámico decolonial (México, D.F.: Akal, 2017), 24. La formulación de Adlbi Sibai se basa en Nelson Maldonado-Torres, Sobre la colonialidad del ser: contribuciones al desarrollo de un concepto, en El giro decolonial. Reflexiones para una diversidad epistémica más allá del capitalismo global, ed. S. Castro-Gómez y R. Grosfoguel (Bogotá: Siglo del Hombre, 2017) y María Lugones, “Colonialidad y género," Tabula Rasa 9 (julio-diciembre 2008), 73-101. Ver también Aníbal Quijano, “Colonialidad del poder, eurocentrismo y América latina,” en Colonialidad del saber, eurocentrismo y ciencias sociales, ed. E. Lander (Buenos Aires: CLACSO-UNESCO, 2000), 201-46. Walter Mignolo, Historias locales/diseños globales. Colonialidad, conocimientos subalternos y pensamiento fronterizo (Madrid: Akal, 2003).

2 Anne McClintock, "The Angel of Progress: Pitfalls of the Term 'Post-Colonialism," Social Text, 31/32 (1992): 84-98.
} 
construcción histórica compleja en cuya configuración los sujetos, las epistemologías y las estructuras socio-políticas colonizadas jugaron un papel relevante. Sugeriré la utilidad de emplear la historia como herramienta principal para explicar y conceptualizar lo colonial; no como la confirmación teleológica del mundo post-colonial, sino como la ventana para entender cómo funcionaron los procesos de negociación, dinámicos y heterogéneos. Propondré un marco teórico en que lo colonial no sea concebido como una creación metropolitana exportada a las colonias, y daré ejemplos de trabajos que así lo han abordado, en particular aquellos centrados en el caso del Marruecos colonial. Me detendré en la tensión existente entre privilegiar las experiencias de los sujetos históricos y adoptar una mirada crítica ante dichas perspectivas, especialmente en relación al peligro de reforzar discursos colonialistas y esencialistas. Plantearé la utilidad de dar visibilizad a la heterogeneidad de perspectivas y experiencias, por un lado, y realizar comparativas histórico-espaciales, por otro. Al final del artículo, desarrollaré algunos ejemplos empíricos en relación al género y la propuesta del historiador Mohamed Ennaji de "desacralizar la historia".

La historiografía que celebraba las conquistas militares europeas sobre las poblaciones colonizadas 'retrasadas' o 'bárbaras' proliferó hasta la década de 1930 y 1940. Con el auge del nacionalismo político y las luchas por la independencia surgieron las historiografías nacionalistas que cuestionaban los preceptos coloniales. Especialmente tras la obtención de las independencias, los discursos nacionalistas comenzaron a disputar la legitimidad de las empresas coloniales. Ante la ausencia o la caricaturizada representación de las poblaciones colonizadas que había reinado hasta entonces, las historiadoras nacionalistas procedieron a desenterrar lo que llamaron 'el punto de vista nativo.' No obstante, la mayoría de las voces que esas historias nacionalistas rescataron se limitaban a las élites urbanas masculinas y a los hombres de estado. En esas primeras formulaciones nacionalistas, la población colonizada tendía a aparecer exenta de su capacidad de decisión y acción (agency) histórica y política, por ser concebida como víctima de una fuerza superior bajo el yugo de la cual había sucumbido.

En el caso de la narrativa histórica del Marruecos y el Magreb colonial, la historiografía colonial y/o colonialista y la nacionalista eran antitéticas pero compartían gran parte de los fundamento. ${ }^{3}$ Como sucedió también en otras latitudes, las historiografías nacionalistas magrebíes se oponían a las premisas colonialistas, pero mantenían el marco y la base discursiva sobre la que se construía el relato histórico. Por lo tanto, el valor de cada una de las categorías dicotómicas se subvertía, pero las categorías en sí quedaban intactas. Además, las primeras ponían en valor el carácter beneficioso del colonialismo y las segundas condenaban la violencia que ésta conllevó, pero el denominador común era que el colonialismo se antojaba como una fuerza imparable accionada unas potencias europeas dinámicas, ante las cuales las poblaciones colonizadas parecían haber sido incapaces de actuar; hasta que, con el auge del nacionalismo y las luchas anticoloniales, despertaban del letargo. Aunque supuestamente

\footnotetext{
${ }^{3}$ Para las narrativas colonialistas y nacionalistas, así como la emergencia de nuevas direcciones en la investigación histórica del Magreb, se puede ver: Ali Abdullatif Ahmida, Beyond Colonialism and Nationalism in the Maghrib: History, Culture, and Politics (New York: Palgrave, 2000); Michel Le Gall y Kenneth J. Perkins, The Maghrib in Question: Essays in History \& Historiography (Austin: University of Texas Press, 1997).
} 
los proyectos colonialista y nacionalista eran contrapuestos, ambos reforzaban el poder, el dinamismo y la fuerza de los colonizadores; e implícita o explícitamente rechazaban dichas cualidades en los pueblos colonizados.

En las últimas tres-cuatro décadas, los estudios de lo colonial han recobrado fuerza, especialmente en las disciplinas histórica, literaria y antropológica, y muchos de los conceptos y categorías analíticas utilizadas hasta entonces han sido puestas en tela de juicio. Como resultado de las investigaciones feministas, de los estudios de las minorías y de los estudios culturales y postcoloniales, los estudios coloniales vuelven a estar en el centro del interés investigador. La influencia del grupo de Estudios Subalternos indio, establecido en los años 80, fue muy importante a la hora de establecer los intereses y enfoques de los estudios postcoloniales. En el Magreb, los trabajos teóricos y literarios de intelectuales como Abdelkebir Khatibi, Assia Djebar, Rachid Boudjedra, Fatima Mernissi y Boualem Sansal también han constituido importantes contribuciones a las teorías postcoloniales, así como al feminismo interseccional. ${ }^{4}$ Además, en las últimas décadas del siglo XX, el alcance de las investigaciones históricas se amplió a través del estudio de fuentes y sujetos históricos que no se habían tenido en cuenta hasta entonces. El enfoque interdisciplinar también ayudó a cuestionar algunas de las formulaciones lineares precedentes, y a hacer hincapié en la complejidad tanto de los procesos coloniales como de la sociedad, la cultura, la economía y la política de las poblaciones colonizadas, y a establecer conexiones entre las diferentes fases del continuum histórico en el cual se sitúa el colonialismo.

Es importante reconocer las trayectorias históricas de las diferentes culturas académicas desde los que dichos estudios coloniales han surgido, puesto que éstas han marcado el carácter de los mismos. En el caso español, las aportaciones de la crítica postcolonial no han tenido un gran eco, sobre todo si lo comparamos con el mundo anglosajón. Ello se debe, en parte, a que los estudios postcoloniales se han erigido en lo que Miguel Mellino ha denominado un campo "Anglo-euro-céntrico" y que Gonzalo Fernández Parrilla ha calificado de "imperialismo meta-teórico lingüístico, es decir la hegemonía de la teoría en inglés." "Los estudios postcoloniales, a su vez, se han centrado predominantemente en el colonialismo contemporáneo británico y francés, y han dejado desatendidos otros casos, como el español, el italiano o el alemán. Por otro lado, el "pensamiento decolonial" arriba citado se ha desarrollado en el ámbito latinoamericano en las últimas dos décadas por parte de autores como Aníbal Quijano, Enrique Dussel,

\footnotetext{
${ }^{4}$ Ver, por ejemplo, Abdelkebir Khatibi, La mémoire tatouée: roman (Rabat: Okad, 2007 [1971]); Abdelkebir Khatibi, "Double criticism: the decolonization of Arab sociology," Contemporary North Africa: Issues of Development and Integration, 1985: 9-19; Assia Djebar, Ces voix qui m'assiègent: en marge de ma francophonie (Paris: Albin Michel, 2014 [1999]); Rachid Boudjedra, La prise de Gibraltar: roman (Paris, Denoël, 1987); Boualem Sansal, Poste restante: Alger. Lettre de colère et d'espoir à mes compatriots, (Paris: Editions Gallimard, 2006).

${ }^{5}$ M. Mellino, "Italy and Postcolonial Studies: A Difficult Encounter," Interventions: International Journal of Postcolonial Studies 8, 3 (2006): 461-471; Gonzalo Fernández Parrilla, "Disoriented Postcolonialities: With Edward Said in (the Labyrinth of) Al-Andalus," Interventions 20, 2 (2018): 229-42. Ver también: Waïl S. Hassan y Rebecca Saunders, "Introduction, Part I: The Project of Comparative (Post)Colonialisms," Comparative Studies of South Asia, Africa and the Middle East 23, 1 (2003): 18-31; Hosam M Aboul-Ela: "Is There an Arab (Yet) in This Field?: Postcolonialism, Comparative Literature, and the Middle Eastern Horizon of Said's Discourse Analysis," MFS Modern Fiction Studies 56, 4 (2010): 729-50.
} 
María Lugones, Walter Mignolo y Ramón Grosfoguel, entre otros, cuya producción es en castellano además de en inglés, y que recientemente ha inspirado trabajos en torno a lo islámico. ${ }^{6}$ Analizaré algunos de estos y otros trabajos en las secciones que siguen, sobre todo en tanto en cuanto me permitan delinear las propuestas teórico-metodológicas para abordar el estudio del pasado colonial como paso previo a descolonizar las dinámicas neocoloniales actuales.

\section{Propuestas teórico-metodológicas para abordar "lo colonial". Historiar la colonización}

Propongo historiar como herramienta metodológica para evitar el determinismo, para construir narrativas matizadas sobre tendencias, operaciones, prácticas, luchas, negociaciones y convergencias históricas que nos ayuden a explicar cuáles eran las nociones prevalentes, qué significaban para los diferentes sectores sociales, y cómo se fue gestando el cambio. Historiar para evitar grandes narrativas - más prescriptivas que analíticas o explicativas - que homogenizan toda una serie de procesos históricos bajo supuestos denominadores comunes abstractos, como "modernidad", "identidad", "globalización". Ésta es la crítica que hace Frederick Cooper en su Colonialism in Question, que pone énfasis en "la doble oclusión que se desprende del hecho de convertir la secular colonización europea allende los mares en una crítica a la Ilustración, la democracia o la modernidad. En primer lugar, se oculta la historia europea, ya que la otra cara de reducir la historia no-occidental a la falta de lo que Occidente sí tenía es que se asume que, efectivamente, Occidente lo tenía [la democracia, la modernidad, etc.] [...] En segundo lugar, se oculta la historia de las personas que vivían en las colonias".?

Las implicaciones epistemológicas y políticas que tiene esa "doble oclusión" en que se centra Cooper son claves a la hora de poner en práctica una metodología descolonizadora. Reducir la complejidad de la historia europea y fundirla en esencias totalizadoras imposibilita ver el carácter de negociación que muchos procesos y conceptos, incluida la colonización, tuvieron en distintas épocas, lugares y comunidades. Además, refuerza un universalismo falaz y refuerza una linealidad y una homogeneidad, en este caso europea, que son constructos y no realidad histórica. La Europa a-histórica emerge con una fuerza y coherencia mayor de la que nunca tuvo y refuerza una forma de eurocentrismo, porque a esa todopoderosa Europa se le atribuye la capacidad de intervenir, moldear y contaminarlo todo, o casi todo.

Al contraponer esa Europa todopoderosa a las colonias, éstas emergen como meras víctimas. En el espejo de una Europa a-histórica, los espacios, las personas, las epistemes y las prácticas colonizadas se conciben también como esencias y como exentas de toda agencia y desposeídas de historia. No obstante, "entre las poblaciones metropolitanas, los colonizados a veces suscitaban compasión o pena, a veces miedo - y sentimientos mucho más complejos, que surgieron en encuentros y en luchas políticas

\footnotetext{
${ }^{6}$ Sirin Adlbi Sibai, La cárcel del feminismo; Houria Boutedjla, Los blancos, los judios y nosotros: hacia una política del amor revolucionario (Ciudad de México, Akal, 2017).

${ }^{7}$ Frederick Cooper, Colonialism in Question: Theory, Knowledge, History, Berkeley, University of California Press, 2005: 15-16.
} 
que tuvieron lugar en las propias colonias." ${ }^{8}$ Reconocer esto es reconocer la capacidad de decidir y actuar de las poblaciones colonizadas; pero no sólo en cuanto a su resistencia, como si fuera una mera respuesta, sino como acción e influencia que ejercieron desde un primer momento en las formas que adoptó la colonización.

Historiar implica concebir lo social, lo cultural y lo político como dinámico, en constante transformación. Si precisamente los discursos imperiales decimonónicos hacían hincapié en el carácter estático y sin historia de aquellos países, pueblos y culturas que colonizaron o que pretendían colonizar, una perspectiva descolonizadora debería reforzar el dinamismo de las sociedades y las culturas colonizadas, hacer hincapié en el constante cambio y complejidad que las caracterizaba y alejarse de las tesis que asumen el supuesto carácter 'civilizado' o 'moderno' de las colonizadoras y el 'bárbaro' o 'tradicional' de las colonizadas. En vez de subrayar y reforzar estas falacias, las metodologías descolonizadoras deberían centrarse en explicar cómo se construyeron las reivindicaciones y discursos que perpetuaban jerarquías sociales; de-construir las falacias en las que se basaban y que reproducían, lo que éstas ocultaban y que deberíamos conocer para tener una visión más amplia y crítica de los argumentos que se usaron para legitimar la colonización, así como de las prácticas que la constituyeron.

Este alegato a favor de historiar no es una defensa de la disciplina histórica en sí, sino una invitación a que 'nos pongamos las gafas históricas' en nuestros análisis. No se trata tanto de que todas nos sumerjamos en el estudio de la historia, o, mejor dicho, las historias, en plural y en femenino, ${ }^{9}$ sino de que aquello que estudiemos lo hagamos teniendo en cuenta la historicidad de los procesos que estudiamos. Si nos centramos en los procesos además de lo discursivo, podemos ver el carácter negociado de los regímenes y las prácticas políticas coloniales u otras. La antropóloga Ann Stoler, por ejemplo, en su trabajo sobre la construcción de las políticas, los discursos y las prácticas coloniales en las Indias Orientales Neerlandesas concibe el archivo como un proceso, no un objeto. ${ }^{10}$ Stoler sostiene que la administración colonial funcionaba a partir de elementos emocionales y de una episteme de la incertidumbre, no sólo ni predominantemente de la 'verdad.' Y nos invita a ver los archivos "no como un almacén del poder estatal, sino como los movimientos inquietos que se producen en un campo de fuerza en el que las personas y las creencias en las que se basaban se realinean y se reajustan como espacios en que los sentidos y lo afectivo fluye a través de las aparentes abstracciones de las racionalidades políticas." 11

La propuesta de Stoler de concebir el archivo como un proceso complejo en el que los elementos emocionales y en especial la incertidumbre son centrales en la configuración del poder resulta sugerente a la hora de plantearnos los procesos y los espacios que queremos descolonizar, sean estos académicos o no: aulas, asambleas,

\footnotetext{
${ }^{8}$ Ibid., 24.

${ }^{9}$ En inglés, el término herstory (que sustituye el prefijo masculino "his" por el femenino "her") señala el androcentrismo de las narrativas históricas hegemónicas (que hacen que la historia sea, literalmente, la "de él/ellos") y propone feminizarlas.

${ }^{10}$ Ann Stoler, Along the Archival Grain: Thinking through Colonial Ontologies (Princeton, N.J.; Woodstock, Princeton University Press, 2008).

${ }^{11}$ Ibid., 33.
} 
barrios, hogar, espacios públicos, etc. En definitiva, el método que propongo para descolonizar a través de historiar consistiría en gran medida en no reproducir una supuesta fuerza, hegemonía y homogeneidad europea que oculte, haga homogéneo y precarice el ámbito colonizado, sino en hacer hincapié en el carácter negociado de los procesos coloniales, en ese constante reajuste e incertidumbre que lo constituía.

\section{Más allá de los macro modelos: la colonización desde lo local y lo pre-colonial}

Hacer hincapié en la historicidad de lo colonial es poner el acento en el proceso de construcción y negociación a través del cual emergieron formas específicas coloniales. Entraña, también, atender a las coyunturas históricas concretas en que se produjo dicha colonización, así como a la posición de las metrópolis y las regiones colonizadas. Los estudios postcoloniales, al centrarse casi exclusivamente en el colonialismo moderno francés y británico, han contribuido al establecimiento de un "modelo europeo general" de colonialismo moderno. El establecimiento de un modelo de colonialismo europeo es problemático por varias razones. Por un lado, se elimina toda historicidad del proceso de colonización, por lo que el proyecto descolonizador pierde las cualidades específicas por las cuales ha sido constituido; algo que está relacionado con la tesis de Cooper comentada anteriormente. Estos modelos coloniales, además, relegan una vez más lo colonizado a mero receptor pasivo de lo que la potencia colonial le impone.

El segundo aspecto problemático de definir lo colonial en base a un 'modelo' de colonialismo y señalar la variante excepcional es que suele acabar reproduciendo el discurso colonial. ${ }^{12}$ En el Prólogo de la edición española de Orientalism, un texto fundacional de los estudios postcoloniales, Edward Said afirmó que España constituyó una "notable excepción" al colonialismo europeo. ${ }^{13}$ Said atribuía dicha excepcionalidad al pasado islámico de España. Lo que el destacado intelectual quizás ignoraba es que dicho argumento fue clave a la hora de legitimar la colonización española en África, ya que España decía poseer unos 'derechos históricos y geográficos' que las demás potencias carecían. ${ }^{14}$ Era el supuesto carácter excepcional del colonialismo español en Marruecos, precisamente, lo que las autoridades coloniales proclamaban tanto en el siglo XIX, cuando las aspiraciones coloniales enfrentaban a las potencias europeas entre sí, como en el siglo XX, una vez se estableció el doble Protectorado franco-español. ${ }^{15}$ Ello incluía hacer hincapié en la excepcionalidad y docilidad española frente, especialmente, Francia. El franquismo, aislado en el ámbito internacional, invirtió muchos recursos en dicha retórica propagandística. ${ }^{16}$

12 Gonzalo Fernández Parrilla y Carlos Cañete, "Spanish-Maghribi (Moroccan) relations beyond exceptionalism: a postcolonial perspective," The Journal of North African Studies 24, 1, 2019: 111-133.

${ }^{13}$ Edward W. Said, Orientalismo (Madrid: Penguin Random House Grupo Editorial España, 2002): 9-10.

14 Víctor Morales Lezcano, "Las relaciones hispano-marroquíes en el siglo XIX," en Historia de Marruecos: de los orígenes tribales y las poblaciones nómadas a la independencia y la monarquía actual (Madrid: La esfera de los libros, 2006): 181-202.

${ }^{15}$ Eric Calderwood, Colonial Al-Andalus: Spain and the Making of Modern Moroccan Culture (Cambridge, Massachusetts: Harvard University Press, 2018).

${ }_{16}$ Miguel Hernando de Larramendi, Irene González González y Bernabé López García, El Instituto Hispano-Árabe de Cultura: orígenes y evolución de la diplomacia pública española hacia el mundo árabe (Madrid: AECID, 2015). 
No cabe duda de que tanto el pasado andalusí como las constantes interacciones históricas ibero-magrebíes hicieron que la colonización hispano-marroquí moderna se desarrollara de la forma en la que lo hizo. Lo que me interesa recalcar aquí, sin embargo, es que a la luz del uso colonial que se ha hecho del "pasado compartido" hispanomarroquí, resulta imperioso que seamos conscientes del efecto perverso que la narrativa histórica que construimos podría consolidar, en este caso el discurso colonial que dotaba, o por lo menos pretendía dotar, al proyecto colonial de legitimidad. Algo parecido ocurre con los discursos que afirman la existencia de 'puentes' y romantizadas conexiones entre los espacios mediterráneos y las orillas norte y sur del estrecho de Gibraltar. ${ }^{17}$ Romantizar interacciones complejas puede entrañar un lavado de cara de los procesos y los proyectos que también generaron (y generan) jerarquías, exclusiones y violencia.

Si señalar la excepcionalidad refuerza el modelo, concebirlo no solo como un todo homogéneo sino desde las categorías actuales no es menos problemático. Algunas de las articulaciones de quienes se sitúan en la órbita de los anteriormente mencionados estudios coloniales latinoamericanos recrean una ilusión de homogeneidad y estabilidad y eliminan todo signo de proceso y de negociación histórica que todo proyecto y sistema requiere y a través del cual se forma y va transformándose. Según Ramón Grosfoguel,

un hombre europeo capitalista/militar/cristiano/patriarcal/blanco/heterosexual llegó a las Américas y estableció simultáneamente en el tiempo y en el espacio varias jerarquías globales interrelacionadas [...] una particular formación de clase global [...] una jerarquía racial/étnica global [...] una jerarquía de género global. ${ }^{18}$

Tal y como lo explica el autor puertorriqueño, parece que los conquistadores españoles del siglo XV y XVI llegaron a las Américas con una lista de objetivos, y que para cumplirlos tenían estrategias bien pensadas y trazadas; algo que no ayuda a entender los complejos mecanismos por los cuales opera el poder, en general, y el colonialismo, los colonialismos, en particular. De la cita también se desprende que lo metropolitano llega e impone sus valores en lo colonial, lo cual las convierte "globales". ${ }^{19}$ La manera unidireccional en que Grosfoguel concibe que se produjeron las imposiciones es problemática en cuanto refuerza la omnipotencia que se auto-abrogaba el discurso colonial y que, en realidad y en la práctica, era mucho más precaria, limitada y recelosa. Hace más de una década y medio, la ya citada Stoler afirmó que el trabajo de las jóvenes investigadoras se encaminaba hacia hacer ver que las innovaciones en formas políticas, reformas sociales y formas de vida moderna no eran "exportaciones e invenciones europeas sino que, a menudo, viajaban en sentido contrario." 20

\footnotetext{
${ }^{17}$ En este sentido, se puede ver la crítica al concepto eurocentrismo de cosmopolitismo en el caso de la ciudad egipcia de Alejandría en Hala Halim, Alexandrian Cosmopolitanism: An Archive (New York: University of Virginia Press, 2013).

${ }^{18}$ Ramón Grosfoguel, "The Epistemic Decolonial Turn: Beyond Political-Economy Paradigms,” Cultural Studies 21, 2-3 (2007): 216 (211-223).

${ }^{19}$ En Ibid, 217 afirma que "[e]l siglo XVI da inicio a una matriz de poder colonial global que para finales del siglo XIX ya cubría todo el planeta."

${ }^{20}$ Ann Stoler, "Tense and Tender Ties: The Politics of Comparison in North American History and (Post)Colonial Studies," The Journal of American History 88, 3 (2001): 848 (829-865). Para ver la influencia que los discursos y las prácticas de las colonias tuvieron en lo metropolitano, se puede ver: Catherine Hall, At Home with the Empire: Metropolitan Culture and the Imperial World (New York: Cambridge Univ. Press, 2009).
} 
Las aportaciones del "giro espacial" y el "giro local" son claves a la hora de entender "lo bidireccional" a la que alude Stoler y, sobre todo, para poner en tela de juicio la extendida idea de que el colonialismo es el resultado de un compendio de imposiciones externas previamente confeccionadas e importadas al espacio colonial. ${ }^{21}$ Francisco Javier Martínez Antonio, por ejemplo, ha sugerido que concibamos las relaciones coloniales y las internacionales como "los extremos de un continuo relacional," en vez de como dos modelos de relaciones opuestos. ${ }^{22}$ Basándose en las relaciones entre la península y la España ultramarina, por un lado, y en aquellas entre la península y la España africana, por otro, ha sostenido que "la singularidad del imperio español" del siglo XIX reside en el "carácter intermedio entre las grandes potencias mundiales y aquellas formaciones sociales colonizadas o en vías de colonización en Asia y en África." ${ }^{23}$ La supuesta "singularidad" del imperio español no la convertiría en excepcional, sin embargo, ya que lo español podría compararse con los imperios austro-húngaro, otomano, jerifiano (Marruecos), persa y chino. ${ }^{24}$ Martínez Antonio destaca, además, que el proyecto de regeneración hispano-marroquí de finales del siglo XIX “implicaba [...] aceptar y promover un papel relativamente activo de las elites de Marruecos en el proceso." 25

Para seguir ahondando en esta idea de la implicación y la influencia de la cultura y sociedad colonizada sobre la colonizadora, mencionaré dos estudios de antropología histórica. En su estudio sobre el Congo de mediados del siglo XX, el antropólogo Jonathan Friedman se centra en los clubes de elegancia entre clases bajas urbanas. ${ }^{26}$ Friedman identifica la introducción colonial del concepto de evolués, que hacía referencia a la parte de la población congoleña que adoptaba los valores europeos, especialmente en lo que a la vestimenta se refiere. La vestimenta, como sinécdoque de los valores culturales, operaba como categoría de jerarquización de la población. Sin embargo, Friedman afirma que el fenómeno no puede ser concebido como una mera trasplantación de los valores y categorías coloniales, es decir, metropolitanas, a la colonia, ya que en ésta la vestimenta ya era un instrumento de autodefinición muy importante antes de la colonización. En este sentido, Friedman invita a concebir esta práctica como una de

\footnotetext{
${ }^{21}$ Estas asunciones trascienden el campo de los estudios coloniales, y se reproducen en una multitud de disciplinas y temáticas. A menudo, cuando se habla de fenómenos postcoloniales, se asume lo colonial sólo como imposición unilateral. Por ejemplo, para las políticas lingüísticas en Marruecos, ver: Moha Ennaji, "Language Contact, Arabization Policy and Education in Morocco," en Language Contact and Language Conflict in Arabic (London: Routledge, 2002): 71-86.

${ }^{22}$ Francisco Javier Martínez Antonio, “'Dos dedos de una misma mano’: propuestas para un nuevo análisis de las relaciones entre España y Marruecos a finales del siglo XIX," en Regenerar España y Marruecos: ciencia y educación en las relaciones hispano-marroquíes a finales del siglo XIX, eds. Francisco Javier Martínez Antonio e Irene González González (Madrid: Consejo Superior de Investigaciones Científicas, 2011): 26-27 (22-45).

${ }^{23}$ Ibid, 33.

${ }^{24}$ Ibid, 34.

${ }^{25}$ Ibid, 46.

${ }^{26}$ Jonathan Friedman, "The Political Economy of Elegance: An African Cult of Beauty," en Consumption and Identity (Chur, Switzerland: Harwood Academic, 1994), 167-187. En castellano, se puede ver Jonathan Friedman, "La Economía Política de la Elegancia," en Identidad cultural y proceso global (Buenos Aires: Amorrortu, 2001), pp. 227-249.
} 
"complementariedad en la que un régimen colonial calca una praxis jerárquica ya existente." 27

Por su parte, en su trabajo sobre el Protectorado español en Marruecos, Josep Lluís Mateo Dieste ha hecho hincapié en la necesidad de diferenciar los discursos y las prácticas coloniales. ${ }^{28}$ En el caso de la relación que se establecía entre interventores y autoridades, ha mostrado que los notables no fueron exclusivamente víctimas de la dominación española, sino que "también instrumentalizaron a los administradores españoles para acceder al poder, para conservarlo o para eliminar a facciones rivales." ${ }^{29}$ Además, al hilo de la importancia de lo local en la configuración del modus operandi colonial que nos ocupa, Mateo Dieste afirma que algunas de las prácticas coloniales estaban basadas en lógicas locales pre-coloniales, como es el caso de los mecanismos de acceso al poder de los jefes locales. Antes del establecimiento del Protectorado, el sistema político local se basaba en la búsqueda de alianzas con una fuerza externa de mayor poder, como por ejemplo una facción inter-tribal o el Majzén o el gobierno central encabezado por el sultán. Y aquí viene el calco: en tiempos del Protectorado, las Intervenciones pasaron a ser una más de esas fuerzas supra-tribales con las cuales se efectuaban alianzas en tiempos pre-coloniales.

De manera similar, en mi trabajo sobre la Guerra española sobre Tetuán (1859-60) y la ocupación de la ciudad que le siguió (1860-62), he sostenido que los españoles basaron ciertos discursos y prácticas coloniales sobre praxis y epistemologías existentes en el Marruecos pre-colonial. ${ }^{30}$ Los españoles movilizaron estratégicamente los conflictos existentes entre lo urbano y lo rural, y entre la población judía o musulmana, y se hicieron pasar por defensores de las "civilizadas" gentes urbanas de Tetuán, algunas de las cuales se mostraron atemorizadas por las amenazas de los "salvajes" montañeses; o como garantes de la seguridad de la población judía reducida por la "tiranía" y "barbarie" musulmana. Más allá de lo estratégico, la importancia que lo andalusí tenía como categoría y marca social en Marruecos, y otras partes del Magreb, sugiere que el tropo colonial de la "hermandad hispano-marroquí" basado en el pasado común no pueda concebirse como una invención total y únicamente española; mucho menos una creación metropolitana exportada a la colonia. En Marruecos lo andalusí ha estado históricamente ligado a las "refinadas" prácticas de las élites urbanas, y también definía el supuesto carácter "ilustrado" de los centros urbanos como Tetuán, Fez, o Salé. ${ }^{31}$ Ello, a su vez, implica que los conflictos entre lo urbano y lo rural, por un lado, y las diferencias entre las élites y el vulgo urbano, por otro, estaban de alguna manera relacionadas con la adscripción andalusí.

\footnotetext{
${ }^{27}$ Ibid., 241.

28 Josep Lluís Mateo Dieste, La «hermandad» hispano-marroquí: política y religión bajo el protectorado español en Marruecos (1912-1956) (Barcelona: Bellaterra, 2003).

${ }^{29}$ Ibid., 183.

${ }^{30}$ Aunque el conflicto se denominó Guerra de África en España y Guerra de Tetuán en Marruecos, la denominación que yo adopto responde al carácter de agresión militar unilateral que la guerra tuvo. La tesis no está disponible por ahora, pero la 'mimesis' o el calco que menciono aquí lo he tratado en Itzea GoikoleaAmiano, "Hispano-Moroccan Mimesis in the Spanish War on Tetouan and its Occupation (1859-62)," The Journal of North African Studies 24, 1 (2019): 44-61.

${ }^{31}$ Mohamed El Mansour, Morocco in the Reign of Mawlay Sulayman (Wisbech: Middle East \& North African Studies Press, 1990), 10.
} 
Aunque el grado y la manera en la que lo local moldeó o determinó los discursos y las prácticas coloniales no fue homogénea, como tampoco lo fueron los propios "modelos" y experiencias de colonización, y aunque las clases colonizadoras tendían a atribuirse todo el mérito de lo que se establecía, lo cierto es que las prácticas, el saber y también las relaciones de poder locales conformaron los regímenes coloniales. En qué medida y cómo es una cuestión que el trabajo de campo y las fuentes deberán determinar. Esto plantea retos linguísticos, que podrían solventarse no sólo a través del aprendizaje de las lenguas de las zonas sobre las que trabajamos, sino también mediante la colaboración transnacional e interdisciplinar académica; la enseñanza reglada de lenguas no europeas es también un modo de descolonizar la academia, como lo es el trabajo colectivo. Lo que los trabajos mencionados sí tienen en común es que nos alientan a reconocer la multiplicidad de actores, prácticas y discursos involucrados en la constitución de las prácticas y también de los discursos coloniales.

\section{La colonización como proceso histórico que supera el marco local}

Si bien los discursos y las prácticas coloniales no fueron una exportación de la metrópolis a la colonia, puesto que lo local dio forma a los discursos y las prácticas coloniales, tampoco se trata de concebir lo colonial como meramente local y específicamente situado, ya que lo local, regional y nacional estaba y está imbricado en un sistema mundial moldeado por el imperialismo transnacional. Lo que Mrinalini Sinha denomina el "modelo heurístico de la formación social imperial" se centra en lo concreto de las coyunturas históricas específicas, basadas en dinámicas que estaban "condicionadas pero no predeterminadas" por las estructuras fruto de esa interrelación entre lo micro y lo macro. ${ }^{32}$ De ello se deriva que las nuevas subjetividades, las epistemologías y las relaciones de poder coloniales, así como las post-coloniales, emergieran de esa interrelación entre lo local y lo global-imperial.

En su Beyond Global vs. Local: Economic Politics Outside the Binary Frame, los geógrafos de la economía Julie Graham and Katherine Gibson critican que lo global sea concebido como la fuerza y lo local como el campo en el que ésta se despliega; lo global como lo que penetra y lo local como lo penetrado. ${ }^{33} \mathrm{Y}$ es que lo cierto es que existe una jerarquía que opera en nuestra concepción de lo global y lo local que dificulta explorar su interrelación. Gibson-Graham señala que lo local tiende a ser concebido como lo que se transforma como resultado de la penetración de lo global, y en cambio se asume que lo global queda inalterado en la interacción con lo local. Sin embargo, lo local nunca está fuera de las estructuras macro-políticas globales, pero de la misma manera lo macro se compone y se define a través de lo local. Dicho de otro modo, el sistema macro-político no está "ahí fuera", sino que es constitutivo de "lo de dentro", lo micro, lo individual.

\footnotetext{
${ }^{32}$ Mrinalini Sinha, "Mapping the Imperial Social Formation: A Modest Proposal for Feminist History," Signs: Journal of Women in Culture and Society 25, 4 (2000): 1077-82. La cursiva es mía.

${ }^{33}$ J. K Gibson-Graham, "Beyond Global vs. Local: Economic Politics Outside the Binary Frame," en Andrew Herod y Melissa W. Wright (eds.), Geographies of Power: Placing Scale (Oxford: Blackwell Publishers Ltd, 2002), 25-60.
} 
De manera similar, Ulrike Freitag y Achim von Oppen apuntan que se tiende a asociar lo local con un pasado trasnochado que, a la luz de los discursos sobre la globalización actual, habría que superar. ${ }^{34}$ Además, hablan de "translocalidad" para recalcar que "las interacciones y conexiones entre lugares, instituciones, actores y conceptos tienen unos resultados mucho más diversos y a menudo contradictorios de lo que normalmente se piensa". 35

Todo esto, aplicado al estudio del colonialismo, vendría a significar que el marco y las epistemes imperiales globales influían en las formas locales de colonialismo; pero también que las macro-estructuras imperiales se formaron y fueron y siguen transformándose como resultado de los discursos y las prácticas locales.

El trabajo de Etty Terem sobre el reformismo islámico marroquí de principios del siglo XX también indaga sobre esta interrelación entre lo global y lo local. ${ }^{36}$ Lo global en el caso del trabajo de Terem se refiere al movimiento de reforma que se desarrolló en el heterogéneo mundo islámico en la época colonial. Old Texts, New Practices arroja luz sobre la miríada de cambios que se estaban produciendo en Marruecos desde el siglo XIX, cambios que no se limitaban a aquéllos inducidos por las administraciones coloniales. Terem pone en relación el reformismo islámico marroquí con las tendencias reformistas existentes en otras partes del orbe islámico, y muestra las tensiones entre dichas dimensiones y las nuevas formas de concebir y legislar asuntos tan importantes como las relaciones entre musulmanas y judías, las relaciones de género o los modelos de consumo. Además, se hace eco de la crítica que ha homogeneizado el reformismo musulmán como aquel desarrollado en Egipto y Siria. Ahmad Dallal, por su parte, se acerca a intelectuales musulmanes de distintas partes del orbe islámico y defiende que, lejos de constituir un movimiento y unos discursos homogéneos, el reformismo era variado y bebía tanto de la tradición intelectual islámica compartida, como de conceptos y nociones diferentes entre sí. ${ }^{37}$ Dallal también afirma que el reformismo islámico precedió al encuentro con Occidente. $^{38}$

En definitiva, el potencial descolonizador de las perspectivas que superan lo local reside en que nos hace ver las conexiones entre lo local y las geografías, dinámicas y actores más allá de lo local y de lo estrictamente colonial. Ello diversifica y multiplica las perspectivas de los procesos que estudiamos. En las investigaciones históricas, sobre todo aquéllas en que el pasado que se estudia es lejano, mostrar la diversidad y heterogeneidad de discursos, prácticas y posicionamientos puede no resultar fácil, y sin embargo es fundamental para contrarrestar el lenguaje y el imaginario que perpetúa el orden hegemónico.

\footnotetext{
${ }^{34}$ Ulrike Freitag y Achim von Oppen, Translocality: the Study of Globalising Processes from a Southern Perspective (Leiden; Boston: Brill, 2010), p. 10.

35 Ibid., p. 5.

${ }^{36}$ Etty Terem, Old Texts, New Practices: Islamic Reform in Modern Morocco (Stanford: Stanford University Press, 2014).

${ }^{37}$ Dallal se acerca a Muhammad ibn 'Abd al-Wahhab de Arabia (1703-1787), Shah Wali Allah de India (1703-1762), 'Uthman ibn Fudi de Africa occidental (1754-1817) y el libio Muhammad ibn 'Ali al-Sanusi (1787-1859). Ahmad Dallal, "The Origins and Objectives of Islamic Revivalist Thought, 1750-1850," Journal of the American Oriental Society 113, 3, (1993): 341-59.

${ }^{38}$ Ibid., 359.
} 


\section{Visibilizar lo oculto y favorecer la perspectiva de los sujetos históricos}

Otra forma de no reproducir lo hegemónico aunque sea para criticarlo es dar visibilidad a lo que queda oculto; para ello necesitamos afinar la vista para ver más allá de lo obvio a primera vista. Desde lo literario, Francesca Orsini cuestiona las perspectivas dominantes en el estudio de la world literature que relegan a lo invisible y periférico una gran parte del mundo y de la literatura producida en ésta. El ámbito académico de la "literatura mundial," insiste, reproduce la centralidad de las literaturas occidentales y anglófonas. Ante ello, Orsini toma la propuesta de Doreen Massey de concebir lo social como "las multiplicidades de espacio-tiempo," 39 y afirma que "el silencio no es ausencia," que si nos encontramos con espacios vacíos, tendremos que mirar en algún otro lado; e incluso cuando parecen vacíos, a veces basta con mirarlos de otra manera para ver que están llenos de gente diversa, de gustos e historias y trayectorias múltiples. En este sentido, propone que concibamos la literatura mundial como "situada, plural, necesariamente multilingüe, [y] en constante construcción (always-in-the-making)" que ponga énfasis en esa relación entre lo local y lo global. ${ }^{40}$

Además de afinar la vista à la Orsini, poner en el centro del problema investigador las perspectivas plurales de los sujetos históricos es una condición sine qua non para descolonizar la perspectiva académica. Ello implica renunciar al uso de las metacategorías desarrolladas desde la cátedra académica para poner énfasis en las experiencias y los discursos de los sujetos. Esto está relacionado con lo que las teóricas feministas del conocimiento situado han defendido, es decir, que toda corriente epistemológica y metodológica lleva consigo una serie de argumentos normativos, tanto si se reconocen como tales como si no; por lo que quienes investigamos somos sujetos situados y nuestra posición condiciona las lentes con las que vemos el mundo y aquello que investigamos. ${ }^{41} \mathrm{Al}$ hilo de ello, una perspectiva descolonizadora debería alentarnos a dar un paso atrás y escudriñar las categorías y los marcos conceptuales que usamos, para ver si y cómo los estamos imponiendo sobre aquello que estudiamos.

En el caso de las investigaciones históricas, además, poner en el centro a los sujetos históricos conlleva no "perder de vista las metas de las gentes del pasado, para establecer conexiones o modos de pensar que eran importantes para ellas pero no para nosotras." ${ }^{42}$ Las fuentes hablan de lo que era su mundo y de sus preocupaciones, aspiraciones, deseos, frustraciones; y si miramos sin ponernos eso que he llamado 'las gafas históricas,' podemos no alcanzar a concebir y, sobre todo, podemos minusvalorar su importancia. La perspectiva descolonizadora, en cambio, debiera centrarse en los temas y las categorías pertinentes de la época, no de las de quien investiga. Decía Manuel Gamio: "no sabemos cómo piensa el indio, ignoramos sus verdaderas aspiraciones, lo prejuzgamos con nuestro criterio, cuando deberíamos compenetrarnos del suyo para

\footnotetext{
${ }^{39}$ Doreen Massey, Space, Place and Gender (Hoboken: Wiley, 2013), 268.

${ }^{40}$ Francesca Orsini, "The Multilingual Local in World Literature," Comparative Literature 67, 4 (2015): 61 (345-374).

${ }^{41}$ Sandra G. Harding, The Feminist Standpoint Theory Reader: Intellectual and Political Controversies

(New York; London: Psychology Press, 2004).

${ }^{42}$ Frederick Cooper, Colonialism in Question: Theory, Knowledge, History..., 18.
} 
comprenderlo y hacer que nos comprenda. Hay que forjarse - ya sea temporalmente - un alma indígena". ${ }^{3}$

Un trabajo que desde el campo de las ciencias políticas ha realizado una importante intervención en este sentido es el de Adria Lawrence, centrado en las protestas anti-coloniales en el imperio francés. ${ }^{44}$ En el caso de Marruecos, Lawrence se centra en las tensiones existentes entre las demandas reformistas y nacionalistas, y defiende que el nacionalismo no fue ni la única manera ni la primordial en la lucha anti-colonial. Lawrence afirma que la naturalización del ethos nacionalista ha llevado a etiquetar el reformismo marroquí como "protonacionalismo", cuando en realidad las demandas reformistas diferían de las nacionalistas independentistas. Y es que, según Lawrence, quienes abogaban por la reforma hacían hincapié en la igualdad que debía reinar entre todas las personas sujetas al gobierno francés, que criticaban y hacían frente al autoritarismo francés, pero sin aspirar a la independencia; y sólo cuando se comprobó que dichas demandas reformistas no se alcanzarían el nacionalismo marroquí se centró en el carácter extranjero del gobierno imperial y articuló demandas de independencia. Lawrence propone entender las movilizaciones políticas anti-coloniales como procesos dinámicos y en constante cambio, por un lado; y como endógenos en vez de como causa de la caída de los regímenes, por otro lado. ${ }^{45}$

La propuesta de Gibson-Graham de hacer hincapié en lo no-hegemónico como técnica de resubjetivización, el trabajo de Orsini de rastrear documentos en busca de pistas sobre la existencia de aquello que queda oculto o simplemente no se nombra, basado en la propuesta de Massey de reconocer las multiplicidades que configuran el tiempo y el espacio, y la necesidad de hilar fino a la hora de conceptualizar las demandas y movilizaciones históricas para no caer en la teleología que defiende Lawrence casan con la propuesta de este artículo, en el que estoy defendiendo el potencial descolonizador de historiar y de mostrar la heterogeneidad de visiones y experiencias coloniales, especialmente, aunque no sólo, entre las poblaciones colonizadas.

\section{Desacralizar la perspectiva histórica}

Gran parte de la literatura que lidia con el mundo árabe-musulmán ha tendido a resaltar la importancia de lo religioso, sobre todo lo islámico, no tanto lo judío o cristiano, en dichas sociedades. Fatima Mernissi, cuyo trabajo interdisciplinar, pionero y valiente es muy inspirador, es un buen ejemplo de la tendencia que ha tendido a resaltar el papel

\footnotetext{
${ }^{43}$ Manuel Gamio, Forjando patria: pro nacionalismo (México: Porrúa, 1960), 25, citado en: Alexandre Coello De La Rosa y Josep Lluís Mateo Dieste, Elogio de la antropología histórica: enfoques, métodos y aplicaciones al estudio del poder y del colonialismo (Zaragoza: Editorial UOC, Prensas de la Universidad de Zaragoza), 47. Mateo Dieste y Coello de la Rosa añaden que, al mismo tiempo, Gamio "utilizaba el concepto de 'civilización' como una categoría modernizadora. Así, declaraba que 'para incorporar al indio no pretendamos ‘europeizarlo' de golpe; por el contrario, 'nosotros [debemos ser] un tanto [indígenas], para presentarle, ya diluida con la suya, nuestra civilización, que entonces no encontrarán exótica, cruel, amarga e incomprensible. Naturalmente que no debe exagerarse a un extremo ridículo el acercamiento al indio.' Ibid., 95.

${ }^{44}$ Adria Lawrence, Imperial Rule and the Politics of Nationalism: Anti-Colonial Protest in the French Empire (New York: Cambridge University Press, 2013).

45 Ibid., 223, 226.
} 
central del islam y esencialmente opresor en cuanto al género. ${ }^{46}$ En este sentido, Mohamed Ennaji ha realizado una interesante propuesta que ha denominado "la desacralización de la perspectiva histórica." ${ }^{47}$ Ennaji toma como punto de partida el llamamiento de Mohammed Arkoun a articular un discurso académico crítico sobre el islam y las sociedades de mayoría musulmana que "deconstruya" las interpretaciones más extendidas tanto del islam ortodoxo como de los estudios islámicos. ${ }^{48}$ Según Ennaji, el discurso religioso y sus representaciones "secuestran" la historia, con lo que urge realizar una lectura secular de los textos religiosos para "descodificar, o desvelar, el lenguaje sagrado" de los discursos históricos. ${ }^{49}$

Esta desacralización no implica afirmar que lo religioso es irrelevante en las sociedades, en general, y en las árabe-musulmanas, en particular, sino todo lo contrario: es tan relevante que todo lo empaña, porque muchas relaciones, dinámicas e instituciones se gestan en el seno del marco religioso. Desacralizar la perspectiva histórica entraña desvelar lo que yace tras el omnipotente lenguaje religioso, para despojar de esencialismo aquellas reivindicaciones que pequen de esencialistas, sin al mismo tiempo dejar de reconocer por qué los sujetos históricos las empleaban. Se trata, por tanto, de ver más allá del pomposo lenguaje religioso que a veces oculta las premisas sobre las que se basan ciertas alegaciones. En suma, la propuesta de Ennaji es otra manera de historiar los discursos y los sujetos que los articulan.

Un ejemplo práctico de ello se puede encontrar en la anteriormente mencionada Guerra española sobre Tetuán (1859-60) y la ocupación de la ciudad que le siguió (186062). Antes, durante y después de que el Ejército de África invadiera la ciudad norteña, Tetuán se vio sumergida en conflictos políticos internos que salieron a la luz con la situación bélica y de ocupación de la ciudad. Hubo varios argumentos que los diferentes bandos utilizaron para legitimar sus opiniones y opciones políticas. Estos son algunos ejemplos:

Inmediatamente después de que cayera Tetuán el 6 de febrero de 1860, 'Abd alKabīr al-Fāsī al-Fihrī pronunció una juṭba o sermón en la mezquita-universidad de Qarawīyyīn en Fez, invitando a toda la población tetuaní a abandonar la ciudad. ${ }^{50} \mathrm{Al}$ Fihrī animó a "los musulmanes" a matar a los enemigos 'infieles', y lo hizo indicando la forma negativa de su concepción de jihâd, representado por lo femenino: "no os limitéis

\footnotetext{
${ }^{46}$ Dichos trabajos se sitúan sobre todo al principio de su larga y variada trayectoria académica: Fatima Mernissi, Beyond the Veil: Male-Female Dynamics in Modern Muslim Society (Bloomington: Indiana University Press, 1987); Fatima Mernissi, “The Meaning of Spatial Boundaries," en Reina Lewis y Sara Mills (eds.) Feminist Postcolonial Theory: A Reader (New York: Routledge, 2003), 489-501. Para una perspectiva diferente, ver: Fatima Mernissi, The Veil and the Male Elite: A Feminist Interpretation of Women's Right in Islam, trad. Mary Jo Lakeland (New York: Basic Books, 2006).

${ }^{47}$ Mohammed Ennaji, Slavery, the State, and Islam (Cambridge: Cambridge University Pres, 2013), 242.

${ }^{48}$ Mohammed Arkoun, Rethinking Islam Today (Washington, D.C.: CCAS, Georgetown University, 1987); Mohammed Arkoun, The Unthought in Contemporary Islamic Thought (London: Saqi Books, 2002).

${ }^{49}$ Ennaji, Slavery, the State, and Islam..., 242-44.

${ }^{50}$ El sermón de 'Abd al-Kabīr al-Fāsī al-Fihrī en Mohamed Daoud, Tārīkh Tițwān (La Historia de Tetuán) (Rabat: Universidad Muhammad V, vol. V, 1964), 236.
} 
a vencer como lo hacen las mujeres a través de lágrimas, remordimiento, lamentos, queja y tedio." 51

Un hombre llamado Aḥmad al-Jinwī escribió un poema tras la caída de Tetuán explicando que los hombres tetuaníes habían sacado a sus mujeres de la ciudad para "protegerlas $[\ldots]$ como requiere la religión." 52

En algún momento entre agosto de 1860 y febrero de 1861, los 'ulāma o doctores de la ya mencionada mezquita-universidad de Qarawiyyīn dictaron una fatwa sentenciando que todas las mujeres vírgenes que se habían quedado en la Tetuán gobernada por los cristianos debían abandonar la ciudad. ${ }^{53}$

En todos estos ejemplos, el marco en el que se sitúan los argumentos es el islámico. Tanto en el sermón como en la fatwā el lenguaje empleado es eminentemente religioso, y en el poema se atribuye la 'protección' de las mujeres por parte de los hombres al deber religioso. La contextualización y el análisis minucioso de cada uno de los ejemplos excedería el objeto de este ejemplo práctico, sin embargo cabe destacar, primero, que todos se basaban y al mismo tiempo reinscribían unas concepciones implícitas y binarias de lo que representaba lo femenino y lo masculino. En segundo lugar, no hay nada esencialmente religioso ni secular en las políticas de género que motivaban las proclamas arriba expuestas. Aunque dichos temores se expresaran a través del lenguaje religioso, era la política de género la que regía los mismos. Sin embargo, como se verá a continuación, lo que subyace a todos ellos es una ansiedad en relación a la posible pérdida de privilegios masculinos que la ocupación española podía acarrear.

Para desacralizar estas argumentaciones y sacar a la luz lo que "escondían", las comparativas espaciales y temporales resultan útiles:

Durante la Guerra Fulani que llevó al establecimiento del Califato de Sokoto en los territorios de las actuales Nigeria y Camerún en la primera década del siglo XIX, las mujeres participaron en la contienda bélica y lucharon junto a los hombres. Según Jean Boyd, lo hicieron basándose precisamente en ejemplos de la tradición islámica:

\begin{abstract}
las mujeres sacaron fuerzas de los ejemplos de la familia del Profeta y otras mujeres musulmanas de aquella época: Aisha que había cargado fardos de piel con agua para saciar la sed de los heridos de la batalla de Uhud, Rabi que había ayudado a los heridos en la contienda, Fatima que había limpiado la sangre de la espada del Profeta, Umm Raqida que había realizado vendajes, Umm Amarah que, espada en mano, había luchado en Uhud y Umm Attiya que había cocinado para los compañeros del Profeta en siete batallas. ${ }^{54}$
\end{abstract}

\footnotetext{
${ }^{51}$ Ibid., 237.

52 Anónimo: “El 'Manuscrito de Tetuán’”, s.e., 1860, 9, Al-Khizāna al-Dawūdīyya (Archivo de Daoud).

${ }^{53}$ Sīdī Mufaḍụal Afaylāl, "El diario de Sīdī Mufaụ̣̣al Afaylāl," s.d., s.e., 60, Al-Khizāna al-Dawūdīyya (Archivo de Daoud).

54 Jean Boyd, The Caliph's Sister: Nana Asma'u (1793-1865), Teacher, Poet, and Islamic Leader (London; Totowa, N.J.: F. Cass, 1989), 11-12.
} 
Ochos años antes de la Guerra Española sobre Tetuán, el alfaquí marroquí Muḥammad Ibn Aḥmad al-Khūja escribió una carta sobre las reformas militares en la que afirmó que, en ciertas ocasiones, la jihād era obligatoria "hasta para las mujeres". 55

En 1840, el gran cadí de Fez 'Abd al-Hādī al-'Alawī afirmó que la jihād era responsabilidad individual de todos, incluidas las mujeres. ${ }^{56}$

En 1844, antes de la Batalla de Isly contra los franceses, el sultán marroquí 'Abd al-Raḥmān informó al gobernador de Tánger que la jihād "ya no [era] una responsabilidad comunitaria (fard kifāya) que recayera sobre el Ma[jzé]n, sino que se trataba de una responsabilidad individual (fard 'ayn) de todos y cada uno de los musulmanes, incluyendo mujeres y jóvenes". 57

Estos ejemplos muestran que lo religioso, las prescripciones religiosas, las interpretaciones jurídico-políticas, la historia islámica y la sunna profética, en concreto, se ha interpretado de muchas maneras a lo largo de la historia. Si bien las fuentes de la guerra y la ocupación española de Tetuán (1859-62) indican que las mujeres y lo femenino se concebían como la antítesis de lo político, otros ejemplos históricos de Marruecos y el heterogéneo orbe islámico dan cuenta de la existencia de concepciones y prácticas de otra índole. Si leyéramos las fuentes sin la perspectiva desacralizadora propuesta por Ennaji, podríamos adscribir los discursos y las acciones que en éstos se basaban al islam, lo cual fijaría una idea del islam como esencia que no se correspondería con ni haría justicia a los demás usos del mismo realizados para legitimar posiciones antitéticas a las de la guerra y la ocupación de Tetuán.

\section{Conclusiones}

En la actualidad numerosos debates públicos versan sobre los legados del pasado colonial y las dinámicas neocolonialistas actuales que rigen los micro-racismos en las relaciones sociales, el desigual acceso y condiciones laborales de las personas "racializadas" y blancas, los debates sobre la apropiación cultural por parte de colectivos mayoritarios de manifestaciones culturales de grupos minoritarios, así como de las relaciones internacionales. ${ }^{58}$ En todos estos debates, el uso político de la historia está siendo clave. Este artículo ha hecho hincapié en la importancia de usar la historia como herramienta para conceptualizar lo colonial, ya que la lectura que hagamos del pasado colonial configurará nuestra manera de entender las dinámicas neocoloniales actuales y las propuestas de descolonizarlas, tanto en el ámbito académico, incluidas las aulas, como en el ámbito público, social, mediático, cultural y político.

\footnotetext{
55 Ver la carta de Muhammad Ibn Aḥmad Al-Khūja en: Muḥammad Mannūnn̄̄, Maẓāhir Yaqza-t alMagrhib al-Hadìth (Manifestaciones del Despertar del Marruecos Moderno), vol. I (Beirut; London; Casablanca: Dar al-Gharb al-Islami wa al-Madaris, 1985), 154.

56 Jocelyn Hendrickson, "The Islamic Obligation to Emigrate: Al-Wansharīsī’s Asnā Al-Matājir Reconsidered," (Tesis doctoral, Emory University, 2009), 258.

${ }^{57}$ Amira K. Bennison, Jihad and its Interpretations in Pre-Colonial Morocco: State-Society relations during the French Conquest of Algeria (London; New York: Routledge Curzon, 2002), 117.

${ }^{58}$ Empleo "micro-racismos" como símil de "micro-machismos" para hacer referencia a las actitudes y discriminaciones diarias que a menudo no se entienden como violentas aunque son expresiones racistas.
} 
Uno de las piedras angulares de las propuestas teórico-metodológicas del artículo es, precisamente, no reproducir una fuerza y hegemonía metropolitana que relegue lo colonizado a esencias y una posición de victimismo que oculte su capacidad de acción y de moldear lo colonial. Como alternativa, he sugerido explorar el carácter negociado de los procesos coloniales y visibilizar el constante reajuste e incertidumbre que los constituía. Además, atender a las especificidades de la historicidad de los procesos coloniales implica ir más allá de los macro modelos; de hecho, en el caso del colonialismo español en Marruecos, hacer hincapié en la "excepcionalidad" del mismo con respecto al colonialismo franco-británico puede reforzar el discurso de legitimación colonial, basado en la "hermandad hispano-marroquî́" y el imaginario de la "bondad" española en África. Por ello, he sugerido que puede resultar útil abordar lo colonial desde lo local y precolonial; acercarnos a las prácticas, el saber y también las relaciones de poder que regían el ámbito local colonizado antes de la colonización nos puede servir para cuestionar el alcance del poder que las potencias colonizadoras se abrogaban, y para matizar las rupturas históricas que las historiografías nacionalistas han atribuido a la colonización. Centrarnos en lo local, además, nos brinda la oportunidad de acercarnos a las perspectivas de los sujetos históricos, cuya necesaria heterogeneidad es importante visibilizar para huir de esencialismos y generalizaciones, especialmente en lo relativo a lo colonizado. Al mismo tiempo, lo local colonial no se puede entender si no es en relación a lo globalimperial, ya que la dimensión local y global están relacionadas y la una conforma la otra. Además, el escrutinio de los diferentes espacios y escalas geográficas se puede complementar, como he sugerido, con comparativas trans-históricas que arrojen luz sobre la variedad de transformaciones acaecidas con respecto a un mismo tema o eje a través de la historia. El ejemplo empírico incluido al final del artículo ilustra precisamente la utilidad de dichas comparaciones histórico-espaciales para "desacralizar la perspectiva histórica" à la Mohamed Ennaji: desvelar lo que yace tras el omnipotente lenguaje religioso para despojar de esencialismos las reivindicaciones esencialistas, sin dejar de lado cuándo, por qué y cómo las empleaban los sujetos históricos. La desacralización y las comparaciones histórico-espaciales son especialmente relevantes en el caso de los temas de género y sexualidad, ya que la historiografía y los estudios culturales han solido atribuirle a la religión un papel definitorio en la configuración del sistema sexo-género; y es en nombre de dichos argumentos que se siguen legitimando intervenciones neocoloniales en la actualidad. ${ }^{59}$

\footnotetext{
59 Jasbir K. Puar, Terrorist Assemblages: Homonationalism in Queer Times (Durham; London: Duke University Press, 2007); Joseph Massad, "Re-Orienting Desire: The Gay International and the Arab World," Politics of the Modern Arab World: Critical Issues in Modern Politics of the Modern Arab World, ed. Laleh Khalili, 4 (2009): 343-365.
} 


\section{Bibliografía}

Abdelkebir Khatibi, "Double criticism: the decolonization of Arab sociology," Contemporary North Africa: Issues of Development and Integration, 1985: 9-19.

Abdelkebir Khatibi, La mémoire tatouée: roman (Rabat: Okad, 2007 [1971]).

Ahmad Dallal, "The Origins and Objectives of Islamic Revivalist Thought, 1750-1850," Journal of the American Oriental Society 113, 3, (1993): 341-359.

Alexandre Coello De La Rosa y Josep Lluís Mateo Dieste, Elogio de la antropología histórica: enfoques, métodos y aplicaciones al estudio del poder y del colonialismo (Zaragoza: Editorial UOC, Prensas de la Universidad de Zaragoza).

Adria Lawrence, Imperial Rule and the Politics of Nationalism: Anti-Colonial Protest in the French Empire (New York: Cambridge University Press, 2013).

Ali Abdullatif Ahmida, Beyond Colonialism and Nationalism in the Maghrib: History, Culture, and Politics (New York: Palgrave, 2000).

Amira K. Bennison, Jihad and its Interpretations in Pre-Colonial Morocco: State-Society relations during the French Conquest of Algeria (London; New York: Routledge Curzon, 2002).

Aníbal Quijano, "Colonialidad del poder, eurocentrismo y América latina," en Colonialidad del saber, eurocentrismo y ciencias sociales, ed. E. Lander (Buenos Aires: CLACSO-UNESCO, 2000), 201-246.

Ann Stoler, "Tense and Tender Ties: The Politics of Comparison in North American History and (Post)Colonial Studies," The Journal of American History 88, 3 (2001): 829865.

Ann Stoler, Along the Archival Grain: Thinking through Colonial Ontologies (Princeton, N.J.; Woodstock, Princeton University Press, 2008).

Anne McClintock, "The Angel of Progress: Pitfalls of the Term 'Post-Colonialism,"” Social Text, 31/32 (1992): 84-98.

Anónimo: “El 'Manuscrito de Tetuán"”, s.e., 1860, 9, Al-Khizāna al-Dawūdīyya (Archivo de Daoud).

Assia Djebar, Ces voix qui m'assiègent: en marge de ma francophonie (Paris: Albin Michel, 2014 [1999]).

Boualem Sansal, Poste restante: Alger. Lettre de colère et d'espoir à mes compatriots, (Paris: Editions Gallimard, 2006). 
Catherine Hall, At Home with the Empire: Metropolitan Culture and the Imperial World (New York: Cambridge Univ. Press, 2009).

Doreen Massey, Space, Place and Gender (Hoboken: Wiley, 2013).

Edward W. Said, Orientalismo (Madrid: Penguin Random House Grupo Editorial España, 2002).

Eric Calderwood, Colonial Al-Andalus: Spain and the Making of Modern Moroccan Culture (Cambridge, Massachusetts: Harvard University Press, 2018).

Etty Terem, Old Texts, New Practices: Islamic Reform in Modern Morocco (Stanford: Stanford University Press, 2014).

Fatima Mernissi, "The Meaning of Spatial Boundaries," en Feminist Postcolonial Theory: A Reader, eds. Reina Lewis y Sara Mills (New York: Routledge, 2003), 489-501.

Fatima Mernissi, Beyond the Veil: Male-Female Dynamics in Modern Muslim Society (Bloomington: Indiana University Press, 1987).

Fatima Mernissi, The Veil and the Male Elite: A Feminist Interpretation of Women's Right in Islam, trad. Mary Jo Lakeland (New York: Basic Books, 2006).

Francesca Orsini, "The Multilingual Local in World Literature," Comparative Literature 67, 4 (2015), 345-374.

Francisco Javier Martínez Antonio, “'Dos dedos de una misma mano’: propuestas para un nuevo análisis de las relaciones entre España y Marruecos a finales del siglo XIX," en Regenerar España y Marruecos: ciencia y educación en las relaciones hispanomarroquies a finales del siglo XIX, eds. Francisco Javier Martínez Antonio e Irene González González (Madrid: Consejo Superior de Investigaciones Científicas, 2011), 2245 .

Frederick Cooper, Colonialism in Question: Theory, Knowledge, History, Berkeley, University of California Press, 2005: 15-16.

Gonzalo Fernández Parrilla y Carlos Cañete, "Spanish-Maghribi (Moroccan) relations beyond exceptionalism: a postcolonial perspective," The Journal of North African Studies 24, 1, 2019: 111-133.

Gonzalo Fernández Parrilla, "Disoriented Postcolonialities: With Edward Said in (the Labyrinth of) Al-Andalus," Interventions 20, 2 (2018): 229-242.

Gurminder K. Bhambra, "Postcolonial and Decolonial Reconstructions", en Connected Sociologies (Londres: Bloomsbuty, 2014), 117-139.

Hala Halim, Alexandrian Cosmopolitanism: An Archive (New York: University of Virginia Press, 2013). 
Hosam M Aboul-Ela: "Is There an Arab (Yet) in This Field?: Postcolonialism, Comparative Literature, and the Middle Eastern Horizon of Said's Discourse Analysis," MFS Modern Fiction Studies 56, 4 (2010): 729-750.

Houria Boutedjla, Los blancos, los judios y nosotros: hacia una política del amor revolucionario (Ciudad de México, Akal, 2017).

Itzea Goikolea-Amiano, "Hispano-Moroccan mimesis in the Spanish war on Tetouan and its occupation (1859-62)," The Journal of North African Studies 24, 1 (2019): 44-61.

J. K Gibson-Graham, "Beyond Global vs. Local: Economic Politics Outside the Binary Frame," en Geographies of Power: Placing Scale, eds. Andrew Herod y Melissa W. Wright (Oxford: Blackwell Publishers Ltd, 2002), 25-60.

Jasbir K. Puar, Terrorist Assemblages: Homonationalism in Queer Times (Durham; London: Duke University Press, 2007).

Jean Boyd, The Caliph's Sister: Nana Asma'u (1793-1865), Teacher, Poet, and Islamic Leader (London; Totowa, N.J.: F. Cass, 1989).

Jocelyn Hendrickson, "The Islamic Obligation to Emigrate: Al-Wansharīsī’s Asnā AlMatājir Reconsidered," (Tesis doctoral, Emory University, 2009), 258.

Jonathan Friedman, "La Economía Política de la Elegancia," en Identidad cultural y proceso global (Buenos Aires: Amorrortu, 2001).

Jonathan Friedman, "The Political Economy of Elegance: An African Cult of Beauty," en Consumption and Identity (Chur, Switzerland: Harwood Academic, 1994).

Josep Lluís Mateo Dieste, La «hermandad» hispano-marroquí: política y religión bajo el protectorado español en Marruecos (1912-1956) (Barcelona: Bellaterra, 2003).

Joseph Massad, "Re-Orienting Desire: The Gay International and the Arab World," Politics of the Modern Arab World: Critical Issues in Modern Politics of the Modern Arab World, ed. Laleh Khalili, 4 (2009): 343-365.

M. Mellino, "Italy and Postcolonial Studies: A Difficult Encounter," Interventions: International Journal of Postcolonial Studies 8, 3 (2006): 461-471.

Manuel Gamio, Forjando patria: pro nacionalismo (México: Porrúa, 1960).

María Lugones, “Colonialidad y género,” Tabula Rasa 9 (julio-diciembre 2008), 73-101.

Michel Le Gall y Kenneth J. Perkins, The Maghrib in Question: Essays in History \& Historiography (Austin: University of Texas Press, 1997). 
Miguel Hernando de Larramendi, Irene González González y Bernabé López García, El Instituto Hispano-Árabe de Cultura: orígenes y evolución de la diplomacia pública española hacia el mundo árabe (Madrid: AECID, 2015).

Moha Ennaji, "Language Contact, Arabization Policy and Education in Morocco," en Language Contact and Language Conflict in Arabic (London: Routledge, 2002): 71-86.

Mohamed Daoud, Tārīkh Tițwān (La Historia de Tetuán) (Rabat: Universidad Muhammad V, vol. V, 1964).

Mohamed El Mansour, Morocco in the Reign of Mawlay Sulayman (Wisbech: Middle East \& North African Studies Press, 1990).

Mohammed Arkoun, Rethinking Islam Today (Washington, D.C.: CCAS, Georgetown University, 1987).

Mohammed Arkoun, The Unthought in Contemporary Islamic Thought (London: Saqi Books, 2002).

Mohammed Ennaji, Slavery, the State, and Islam (Cambridge: Cambridge University Pres, 2013).

Mrinalini Sinha, "Mapping the Imperial Social Formation: A Modest Proposal for Feminist History," Signs: Journal of Women in Culture and Society 25, 4 (2000): 10771082.

Muhammad Mannūnnī, Mazāhir Yaqua-t al-Magrhib al-Hadīth (Manifestaciones del Despertar del Marruecos Moderno), vol. I (Beirut; London; Casablanca: Dar al-Gharb al-Islami wa al-Madaris, 1985).

Nelson Maldonado-Torres, Sobre la colonialidad del ser: contribuciones al desarrollo de un concepto, en El giro decolonial. Reflexiones para una diversidad epistémica más allá del capitalismo global, ed. S. Castro-Gómez y R. Grosfoguel (Bogotá: Siglo del Hombre, 2017)

Rachid Boudjedra, La prise de Gibraltar: roman (Paris, Denoël, 1987).

Ramón Grosfoguel, "The Epistemic Decolonial Turn: Beyond Political-Economy Paradigms," Cultural Studies 21, 2-3 (2007): 211-223.

Sandra G. Harding, The Feminist Standpoint Theory Reader: Intellectual and Political Controversies (New York; London: Psychology Press, 2004).

Sīdī Mufaḍụal Afaylāl, "El diario de Sīdī Mufaḍ̣̣al Afaylāl," s.d., s.e., 60, Al-Khizāna al-Dawūdīyya (Archivo de Daoud).

Sirin Adlbi Sibai, La cárcel del feminismo: hacia un pensamiento islámico decolonial (México, D.F.: Akal, 2017). 
Ulrike Freitag y Achim von Oppen, Translocality: the Study of Globalising Processes from a Southern Perspective (Leiden; Boston: Brill, 2010).

Víctor Morales Lezcano, "Las relaciones hispano-marroquíes en el siglo XIX," en Historia de Marruecos: de los orígenes tribales y las poblaciones nómadas a la independencia y la monarquía actual (Madrid: La esfera de los libros, 2006): 181-202.

Wail S. Hassan y Rebecca Saunders, "Introduction, Part I: The Project of Comparative (Post)Colonialisms," Comparative Studies of South Asia, Africa and the Middle East 23, 1 (2003): 18-31.

Walter Mignolo, Historias locales/diseños globales. Colonialidad, conocimientos subalternos y pensamiento fronterizo (Madrid: Akal, 2003.

\section{Perfil}

Itzea Goikolea-Amiano es investigadora postdoctoral en el Centro de Estudios Culturales, Literarios y Postcoloniales en el SOAS-Universidad de Londres desde 2017. Doctora por el departamento de Historia y Civilización en el Instituto Universitario Europeo de Florencia (Italia) en 2017, sus principales líneas de investigación son: el colonialismo español en Marruecos desde el punto de vista de la historia social, cultural y literaria; la historia de la esclavitud trans-Sahariana y el legado social y cultural de la misma en el Magreb contemporáneo; y la población española y, especialmente, las mujeres conversas al islam en el contexto actual de islamofobia, marcada por el género, local y global.

\section{Profile}

Itzea Goikolea-Amiano is a postdoctoral researcher at the Centre for Cultural, Literary and Postcolonial Studies at SOAS, University of London. She obtained her PhD from the History and Civilization department at the European University Institute in Florence (Italy) in 2017, her main research areas being: modern Spanish colonialism in northern Morocco, colonial culture and literature, society and politics; the history of the transSaharan slavery and its legacy; sub-Saharan populations and cultures in the Maghrib; and Spanish population and especially women converts to Islam in the global and local context of gendered Islamophobia.

Fecha de recepción: 20 de mayo de 2019

Fecha de aceptación: 30 de mayo de 2020

Publicación: 1 de julio de 2020

Para citar este artículo: Itzea Goikolea-Amiano, "A vueltas con la descolonización: propuestas para algunas conceptualizaciones coloniales", Historiografías, 19 (enerojunio, 2020), pp. 41-63. 